\title{
Avaliação da satisfação do usuário quanto ao estado de conservação de conjuntos habitacionais de interesse social do PAR: estudo de caso
}

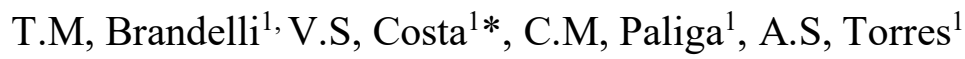 \\ *Autor de Contacto: vitoriascosta@yahoo.com.br \\ ${ }^{1}$ Programa de Pós-graduação em Arquitetura e Urbanismo, Universidade Federal de Pelotas, Pelotas, Brasil.
}

\begin{abstract}
RESUMO
No Brasil, a demanda de moradias da população de baixa renda é suprida por meio da produção de conjuntos habitacionais pelo governo federal. O objetivo é avaliar a percepção do usuário em relação às manifestações patológicas presentes nas fachadas de três conjuntos habitacionais do Programa de Arrendamento Residencial (PAR), na cidade de Pelotas/RS, através de procedimentos metodológicos de Avaliação Pós-Ocupação (APO). Os conjuntos habitacionais têm idade de construção de 16,15 e 14 anos. Foi realizada a APO quanto ao estado de conservação das fachadas, através da aplicação de formulários aos moradores. Verificou-se que a presença de danos - fissuras e trincas, umidade, sujidade e descolamento de revestimento - nas fachadas acarreta maior insatisfação dos moradores com a aparência das edificações.
\end{abstract}

Palavras-chave: Manifestações patológicas; Avaliação pós-ocupação; Habitação de interesse social; Fachadas; Conservação.

\section{RESUMEN}

En Brasil, la demanda de vivienda de la población de bajos ingresos se satisface mediante la producción de proyectos habitacionales por parte del gobierno federal. El objetivo es evaluar la percepción del usuario en relación a las manifestaciones patológicas presentes en las fachadas de tres proyectos habitacionales del Programa de Arrendamiento Residencial (PAR), en la ciudad de Pelotas / RS, mediante procedimientos metodológicos de Evaluación Post-Ocupación (APO). Las urbanizaciones tienen una antigüedad de construcción de 16,15 y 14 años. El APO se realizó sobre el estado de conservación de las fachadas, mediante la aplicación de formularios a los vecinos. Se encontró que la presencia de daños - grietas y grietas, humedad, suciedad y descamación del revestimiento - en las fachadas provoca un mayor descontento entre los residentes con el aspecto de los edificios.

Palabras clave: Manifestaciones patológicas; Evaluación posterior a la ocupación; Vivienda de interés social; Fachadas; Conservación.

\begin{abstract}
In Brazil, the demand for housing of the low-income population is met through the production of housing projects by the federal government. The objective is to evaluate the user's perception in
\end{abstract}


relation to pathological manifestations present on the facades of three housing projects of the Residential Lease Program (PAR), in the city of Pelotas/RS, through methodological procedures of Post-Occupation Assessment (APO). The housing developments have a construction age of 16,15 and 14 years. The APO was carried out regarding the state of conservation of the facades, through the application of forms to the residents. It was found that the presence of damage - cracks and cracks, moisture, dirt and peeling of the coating - on the facades causes greater dissatisfaction among residents with the appearance of the buildings.

Keywords: Pathological manifestations; Post-occupation assessment; Social interest housing; Facades; Conservation.

\section{INTRODUÇÃO}

A indústria da construção civil tem significativo impacto ambiental, social e econômico numa sociedade. As atividades de construção fornecem ao ser humano edificações e instalações que satisfazem suas necessidades, além de proporcionar oportunidades de emprego e contribuir para a economia nacional. Entretanto, junto as vantagens, decorrem o consumo de recursos naturais e energéticos e a geração de poluentes e resíduos durante as atividades de produção, de manutenção e de demolição das edificações (Zuo; Zhao, 2014; John, 2001).

De acordo com a NBR 5674 (ABNT, 2012), para garantir uma maior vida útil, desde o início do uso de uma edificação devem ser realizados serviços de manutenção, sejam eles de caráter rotineiro, corretivo ou preventivo, e que, apesar do custo relevante na fase de uso, devem ser entendidos como investimento na preservação da mesma.

No entanto, no Brasil, as ações de manutenção predial são culturalmente vistas como despesas inconvenientes. As ações normalmente são realizadas somente para correção de falhas ou anomalias, desconhecendo a necessidade de periodicidades das atividades de manutenção preventivas, contribuindo significativamente para a depreciação prematura das edificações (Vieira, 2015). Shimbo e Martins (2002) destacam que, no caso de habitações de interesse social (HIS), os serviços de manutenção não são priorizados pelos programas habitacionais, por objetivar atender critérios mais quantitativos do que qualitativos, simplesmente voltados ao número de unidades habitacionais produzidas. Além disso, a minimização de custos e prazos de construção fazem surgir problemas quanto ao desempenho dos empreendimentos (Stuckert; Sobrinho Junior, 2016).

Na cidade de Pelotas, no Rio Grande do Sul, foram implantados 21 conjuntos habitacionais pelo Programa de Arrendamento Residencial (PAR) entre os anos de 2002 e 2008, de duas tipologias diferentes, uma de casas geminadas de dois pavimentos e outra edifícios de apartamentos de quatro ou cinco pavimentos. Até 2004, o PAR funcionava na modalidade Normal, atendendo moradores na faixa entre três a seis salários mínimos. Porém, objetivando atender uma faixa de renda mais baixa, de dois a quatro salários-mínimos, foi criado o PAR na modalidade Especial, reduzindo as especificações mínimas de projeto e execução. Tal fato alterou a legislação da cidade de Pelotas, permitindo a construção de edificações de até cinco pavimentos sem elevador, que até então eram de no máximo de quatro pavimentos (Chiarelli, 2014).

Avaliação Pós-Ocupação (APO), segundo Medvedovski et al. (2005), pode ser entendida como um método de avaliação dos ambientes construídos que apresenta como principal característica a participação dos usuários no processo de análise. Seu objetivo principal é avaliar o desempenho da edificação em uso, buscando minimizar ou corrigir problemas detectados no ambiente construído utilizando os resultados dessas avaliações como realimentadores do ciclo do processo de projeto, produção e manutenção. De acordo com Roméro e Ornstein (2003), a APO utiliza uma série de métodos e técnicas que diagnosticam fatores positivos e negativos do ambiente no decorrer do uso, levando em consideração o ponto de vista dos avaliadores técnicos bem como dos usuários. Propõe- 
se, portanto, aferir o nível de satisfação dos usuários sem minimizar a importância da avaliação do desempenho, realizando análises, diagnósticos e recomendações a partir de objetos reais.

Baseado no exposto, o presente trabalho teve como objetivo avaliar a percepção do usuário em relação às manifestações patológicas presentes nas fachadas de três conjuntos habitacionais de interesse social do PAR - Residencial Regente, Residencial Jardins da Baronesa e Residencial Estrela Gaúcha - localizados na cidade de Pelotas/RS, através de procedimentos metodológicos de Avaliação Pós-Ocupação (APO).

\section{MÉTODO}

Primeiramente, para o desenvolvimento desta pesquisa e aplicação do método proposto, fez-se necessário a escolha dos objetos de estudo. Os condomínios de habitação de interesse social analisados localizam-se na cidade de Pelotas/RS e foram escolhidos como estudo de caso por serem um dos primeiros residenciais executados. Os residenciais Jardins da Baronesa (Figura 01), Regente (Figura 02) e Estrela Gaúcha (Figura 03) foram entregues nos anos de 2005, 2006 e 2007 e apresentam as características descritas na Tabela 01 .

\begin{tabular}{|l|l|l|l|l|l|}
\hline $\begin{array}{l}\text { Nome do } \\
\text { Conjunto }\end{array}$ & $\begin{array}{l}\mathbf{N}^{\mathbf{0}} \text { de unidades } \\
\text { habitacionais }\end{array}$ & $\begin{array}{l}\mathbf{N}^{\mathbf{0}} \text { de } \\
\text { pav. }\end{array}$ & Modalidade & \multicolumn{1}{c|}{ Implantação } & \multicolumn{1}{c|}{ Entorno } \\
\hline $\begin{array}{l}\text { Residencial } \\
\text { Jardins da } \\
\text { Baronesa }\end{array}$ & 96 & 4 & Normal & $\begin{array}{l}\text { Dois edifícios de quatro } \\
\text { pavimentos. Entre as fitas } \\
\text { estão localizados quadra } \\
\text { esportiva, o playground e } \\
\text { o salão de festas, formado } \\
\text { por uma edificação térrea. }\end{array}$ & $\begin{array}{l}\text { Área } \\
\text { consolidada. Entorno é } \\
\text { cercado por edificações } \\
\text { de pequeno porte. }\end{array}$ \\
\hline $\begin{array}{l}\text { Residencial } \\
\text { Regente }\end{array}$ & 124 & 4 & Normal & $\begin{array}{l}\text { Quatro edifícios de quatro } \\
\text { pavimentos dispostos de } \\
\text { forma periférica no lote, } \\
\text { ao redor de um pátio } \\
\text { central, composto pela } \\
\text { quadra de esportes e pelo } \\
\text { playground. }\end{array}$ & $\begin{array}{l}\text { cercado por edificações } \\
\text { pequeno porte. } \\
\text { Entretanto, ao sul do } \\
\text { conjunto, existem } \\
\text { outros conjuntos } \\
\text { habitacionais. }\end{array}$ \\
\hline $\begin{array}{l}\text { Residencial } \\
\text { Estrela } \\
\text { Gaúcha }\end{array}$ & 300 & 5 & Especial & $\begin{array}{l}\text { Quatro edifícios de cinco } \\
\text { pavimentos dispostos de } \\
\text { forma periférica no lote ao } \\
\text { redor de um corredor } \\
\text { central, os edifícios foram } \\
\text { implantados distantes da } \\
\text { via pública mais ao fundo } \\
\text { do terreno. }\end{array}$ & $\begin{array}{l}\text { Arrea una pouco } \\
\text { consolidada da cidade, } \\
\text { com uma vizinhança } \\
\text { formada por lotes não } \\
\text { edificados. }\end{array}$ \\
\hline
\end{tabular}




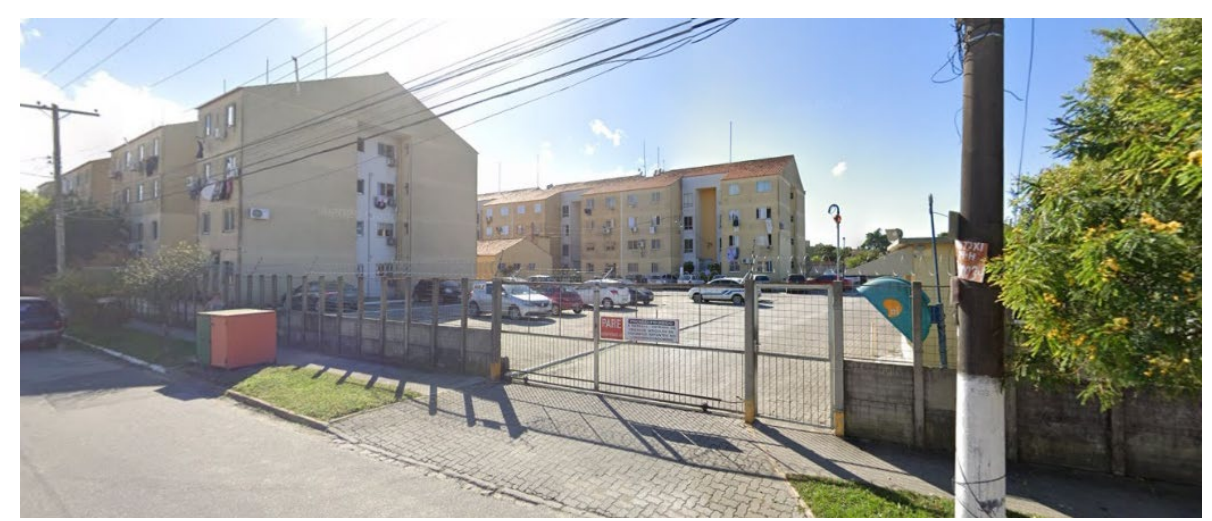

Figura 01 - Portão de acesso do Residencial Jardins da Baronesa. Fonte: Google Earth (2021).

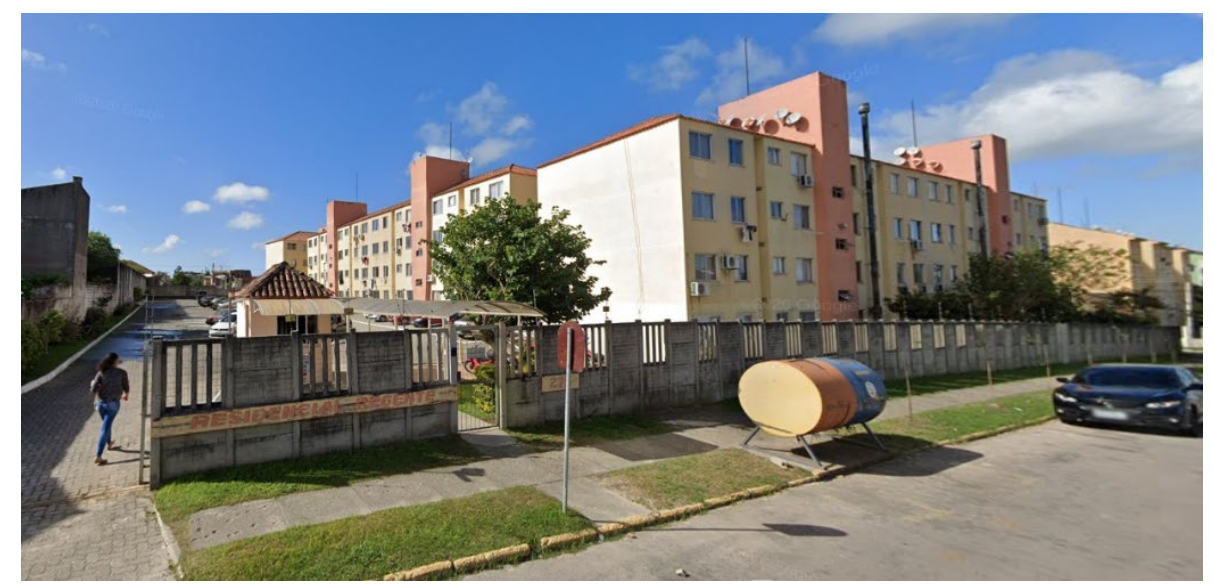

Figura 02 - Portão de acesso do Residencial Regente.

Fonte: Google Earth (2021).

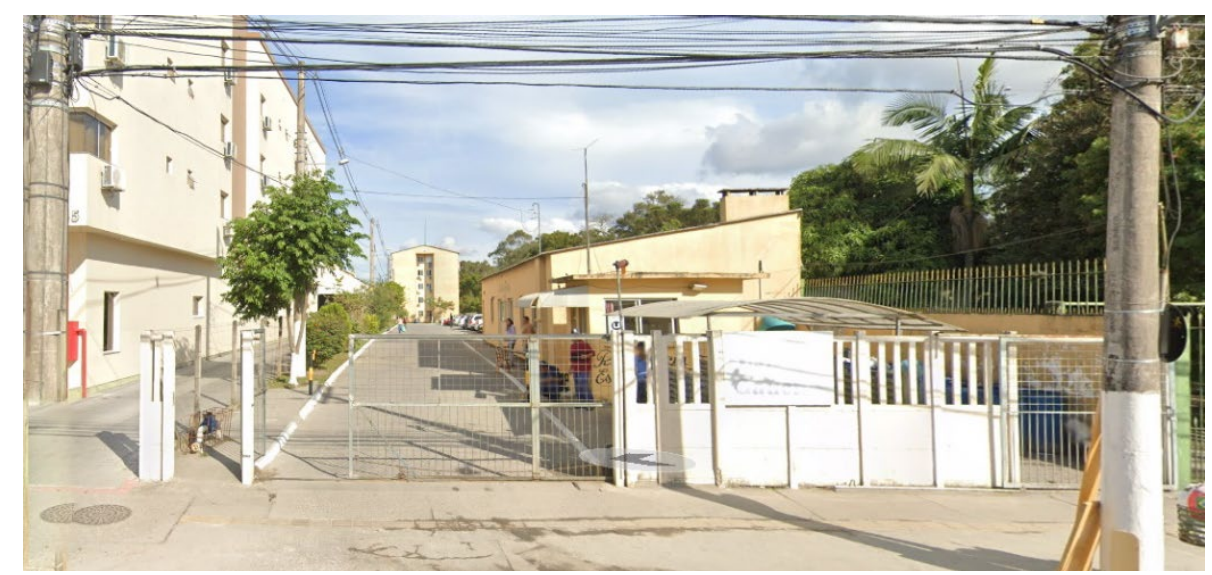

Figura 03 - Portão de acesso do Residencial Estrela Gáucha.

Fonte: Google Earth (2021).

Como método de avaliação da satisfação do usuário foi realizada a aplicação de formulários com os moradores, sendo eles proprietários, arrendatários ou locatários, aplicados nas áreas condominiais. O formulário é o método mais utilizado para obter informações sobre relações entre usuários e ambientes construídos, este instrumento é preenchido com a presença do pesquisador (Roméro; Ornstein, 2003). Ademais, conforme explica Ornstein, Ono e Oliveira (2017), durante a aplicação do formulário, quando o preenchimento é realizado pelo pesquisador, lendo o enunciado 
de cada questão e as alternativas de respostas ao morador e podendo esclarecer eventuais dúvidas, existe maior clareza e inteligibilidade das questões.

Neste estudo foi utilizado o mesmo formulário produzido e empregado por Silva (2016). Conforme a Figura 04, o formulário contempla apenas treze perguntas, sendo as seis primeiras referentes ao morador e as seguintes acerca da situação atual das fachadas, das atividades de manutenção e gestão condominial. Foram adaptadas somente as informações específicas de cada estudo de caso nos formulários, como os blocos e o número de pavimentos do conjunto.

\begin{tabular}{|c|c|}
\hline \multicolumn{2}{|c|}{ 1. Qual bloco você mora? } \\
\hline ( ) & Bloco A \\
\hline$($ ) & Bloco B \\
\hline ( ) & Bloco C \\
\hline ( ) & Bloco D \\
\hline \multicolumn{2}{|c|}{ 2. Qual pavimento você mora? } \\
\hline$($ ) & $1^{\circ}$ (Térreo) \\
\hline () & $2^{\circ}$ \\
\hline$($ ) & $3^{\circ}$ \\
\hline$($ ) & $4^{\circ}$ \\
\hline() & $5^{\circ}$ \\
\hline \multicolumn{2}{|c|}{ 3.Qual seu sexo? } \\
\hline () & Feminino \\
\hline() & Masculino \\
\hline \multicolumn{2}{|c|}{ 4. Qual sua faixa etária? } \\
\hline$($ ) & Até 24 anos \\
\hline () & 25 a 39 anos \\
\hline ( ) & 40 a 59 anos \\
\hline ( ) & Mais de 60 anos \\
\hline \multicolumn{2}{|c|}{ 5. Em relação ao seu apartamento, você é } \\
\hline ( ) & Proprietário \\
\hline ( ) & Inquilino (aluguel) \\
\hline ( ) & Arrendatário \\
\hline \multicolumn{2}{|c|}{ 6. Qual o número de pessoas que moram no seu apartamento? } \\
\hline ( ) & 1 pessoa \\
\hline ( ) & 2 pessoas \\
\hline() & 3 pessoas \\
\hline ( ) & 4 ou mais pessoas \\
\hline \multicolumn{2}{|c|}{$\begin{array}{l}\text { 7. Você já reparou nos problemas (danos) existentes nas fachadas dos prédios do seu } \\
\text { condomínio? }\end{array}$} \\
\hline$($ () & Sim \\
\hline ( ) & Não \\
\hline \multicolumn{2}{|c|}{ 8. Esses problemas incomodam? } \\
\hline ( ) & Sim \\
\hline ( ) & Não \\
\hline \multicolumn{2}{|c|}{$\begin{array}{l}\text { 9. Enumere em ordem de prioridade ( } 1 \text { - muito, } 2 \text { - mais, } 3 \text { - médio, } 4 \text { - menos, 5-pouco) } \\
\text { qual mais chama sua atenção? }\end{array}$} \\
\hline ( ) & $\begin{array}{l}\text { Umidade (bolor-fungo-preto fachada; musgos; limos; manchas esverdeadas; vegetação } \\
\text { parasitária; eflorescências; empolamentos...) }\end{array}$ \\
\hline ( ) & Fissuras/Trincas (horizontais; verticais; inclinadas; mapeadas) \\
\hline ( ) & $\begin{array}{l}\text { Descolamento de revestimentos (reboco ou pintura) (cantos das paredes; contorno de janelas- } \\
\text { grades; buracos de ar-condicionado; antenas ou varais; descolamento de tinta da viga de } \\
\text { fundação, peitoril ou reboco...) }\end{array}$ \\
\hline ( ) & Sujidade (respingos oriundos de janelas; manchas de corrosão; riscos, desenhos ou escritas...) \\
\hline \multicolumn{2}{|c|}{$\begin{array}{l}\text { 10. Você já realizou algum tipo de reclamação para a imobiliária administradora de } \\
\text { problemas ocorridos nas fachadas? }\end{array}$} \\
\hline ( ) & Não \\
\hline ( ) & Sim - Qual? \\
\hline
\end{tabular}




\begin{tabular}{|l|l|}
\hline 11. Você acha que o prédio necessita de manutenção nas fachadas? \\
\hline ( ) & Sim \\
\hline ( ) & Não \\
\hline $\begin{array}{l}\text { 12. De manutenção nas fachadas o que você mais acha necessário? Enumere em } \\
\text { ordem de prioridade (1- mais, 2-mais ou menos, 3- menos) }\end{array}$ \\
\hline ( ) & Lavagem \\
\hline ( ) & Pintura \\
\hline ( ) & Reparos no revestimento (reboco) \\
\hline 13. Como você considera a situação atual das fachadas dos prédios? \\
\hline ( ) & Boa \\
\hline ( ) & Razoável \\
\hline ( ) & Ruim \\
\hline
\end{tabular}

Figura 04. Formulário aplicado aos usuários do condomínio.

Os formulários foram aplicados a uma amostra de 30 pessoas por conjunto habitacional, pois, de acordo com Roméro e Ornstein (2003), num estudo de Avaliação Pós-Ocupação, para os questionários cumprirem satisfatoriamente seus objetivos, não devem ser feitos questionários com amostras inferiores a 30 pessoas.

Após a tabulação dos dados dos formulários no Excel, foi realizado o cruzamento dos resultados, executando uma análise comparativa entre a percepção do usuário e o levantamento de manifestações patológicas que possibilitou avaliar a satisfação dos moradores sobre o atual estado de conservação das fachadas.

Conforme realizado por Silva (2016), para análise dos dados foram conferidos pesos para as respostas dos usuários. Para obter o grau de visibilidade do usuário em relação a cada manifestação patológica foram colocados pesos para cada resposta, para "muito" foi utilizado peso 4, para "mais" peso 3, para "mais ou menos" peso 2 e para "menos" peso 1, resultando na porcentagem de relevância de cada dano para o morador. A fim de obter a porcentagem da necessidade das ações de manutenção por ordem de prioridade, os pesos foram para "mais" peso 3, para "mais ou menos" peso 2 e para "menos" peso 1. Por fim, para o cálculo da satisfação, foi atribuído para "bom" peso 3, "razoável" peso 2 e "ruim" peso 1, obtendo-se a porcentagem de cada categoria.

\section{RESULTADOS}

Nessa seção serão apresentados os resultados provenientes da elaboração da APO dos três conjuntos habitacionais de interesse social do PAR: Residencial Regente, Residencial Jardins da Baronesa e Residencial Estrela Gaúcha.

\subsection{Residencial Regente}

No Residencial Regente, a maioria dos respondentes foram do sexo feminino (80\%) entre 25 e 39 anos $(40 \%)$ e 40 a 59 anos (30\%). A maioria dos respondentes, 67\%, é arrendatário do apartamento, outros $27 \%$ são proprietários e $6 \%$ inquilinos.

Foram aplicados formulários com moradores dos quatro edifícios do Residencial Regente, sendo $34 \%$ dos respondentes dos Blocos $\mathrm{G}$ ou $\mathrm{H}, 30 \%$ dos Blocos $\mathrm{C}$ ou D, $23 \%$ dos Blocos A ou B e $13 \%$ dos Blocos $\mathrm{E}$ ou $\mathrm{F}$, espalhados entre os quatro pavimentos do conjunto, sendo $30 \%$ do $3^{\circ}$ pavimento, $30 \%$ do $1^{\circ}$ pavimento, $27 \%$ do $2^{\circ}$ pavimento e $13 \%$ do $4^{\circ}$ pavimento.

Quanto à quantidade de moradores por unidade habitacional, $40 \%$ dos apartamentos dos moradores respondentes são habitados por duas pessoas, seguidos de $20 \%$ por quatro ou mais pessoas, $20 \%$ por três pessoas e $20 \%$ por uma pessoa. 
Quanto a satisfação do usuário em relação as manifestações patológicas, os moradores foram questionados se já haviam reparado nos problemas existentes nas fachadas dos prédios, sendo que a maioria dos respondentes afirmaram que sim (90\%), e quando questionados se estes problemas lhe incomodavam, $90 \%$ dos moradores responderam que sim.

Os moradores foram questionados sobre qual manifestação patológica chamava mais sua atenção. As respostas estão apresentadas na Figura 05.

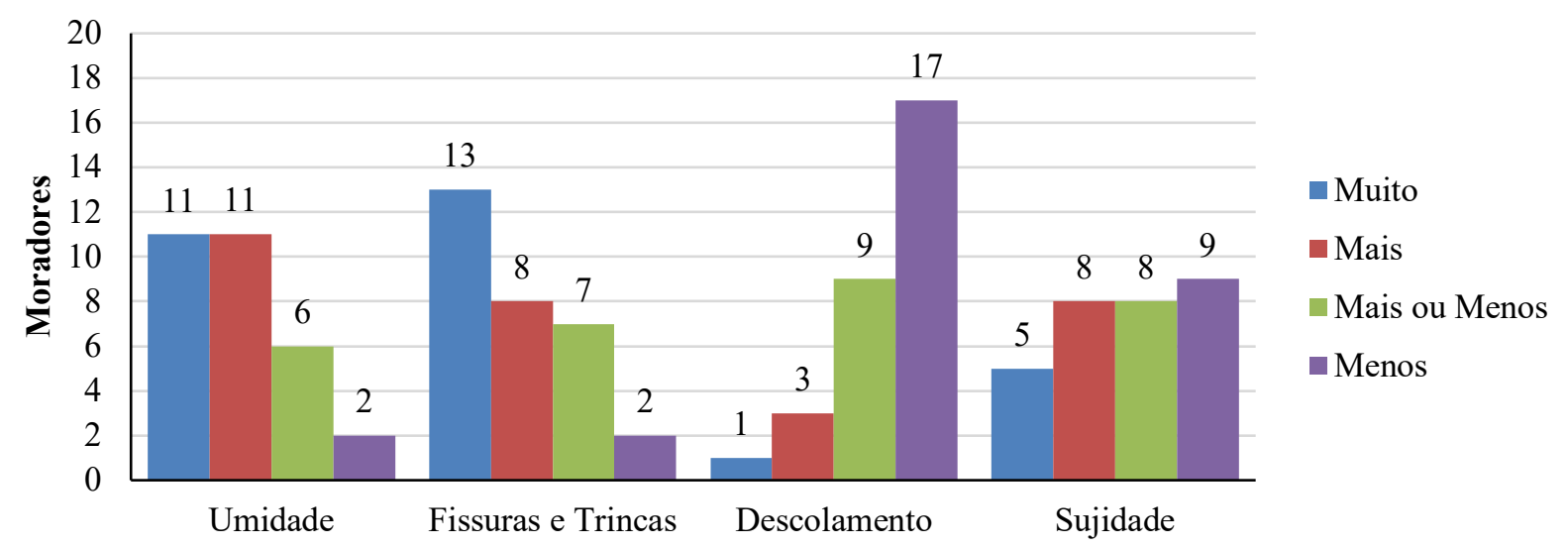

Figura 05. Manifestação patológica mais relevante no Residencial Regente.

Para cada grau de visibilidade do usuário em relação a cada manifestação patológica foram colocados pesos a fim de obter a porcentagem de relevância de cada dano para o morador. De acordo com a Figura 06, as manifestações patológicas que mais chamam a atenção dos moradores são as fissuras e trincas (31\%) e a umidade (30\%), seguido da sujidade (23\%), sendo o descolamento de revestimento a manifestação patológica que chama menos atenção $(16 \%)$.

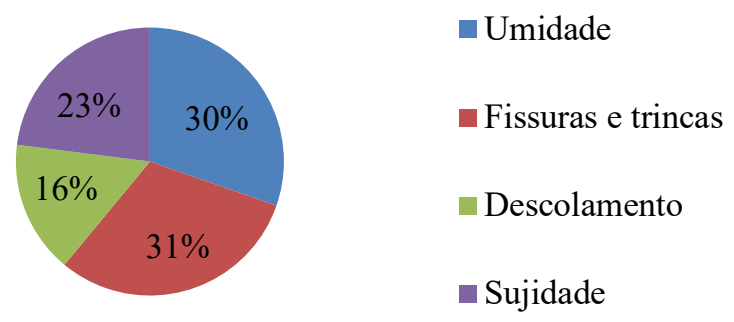

Figura 06. Relevância das manifestações patológicas no Residencial Regente.

A manifestação que mais chama a atenção dos moradores coincide com a manifestação patológica mais incidente, fissuras e trincas. De acordo com Thomaz (1988), os moradores são submetidos ao constrangimento psicológico, com medo de conviver com uma anomalia que pode significar a ruína do seu abrigo.

Sobre a manutenção das fachadas, todos os respondentes consideraram necessárias atividades de manutenção, inclusive os que não haviam reparado nos problemas. Porém, $77 \%$ nunca realizaram algum tipo de reclamação com a imobiliária sobre os problemas das fachadas. Os moradores foram perguntados qual manutenção, entre lavagem, pintura e reparo no revestimento, eles achavam mais necessário, sendo as respostas apresentadas na Figura 07. 


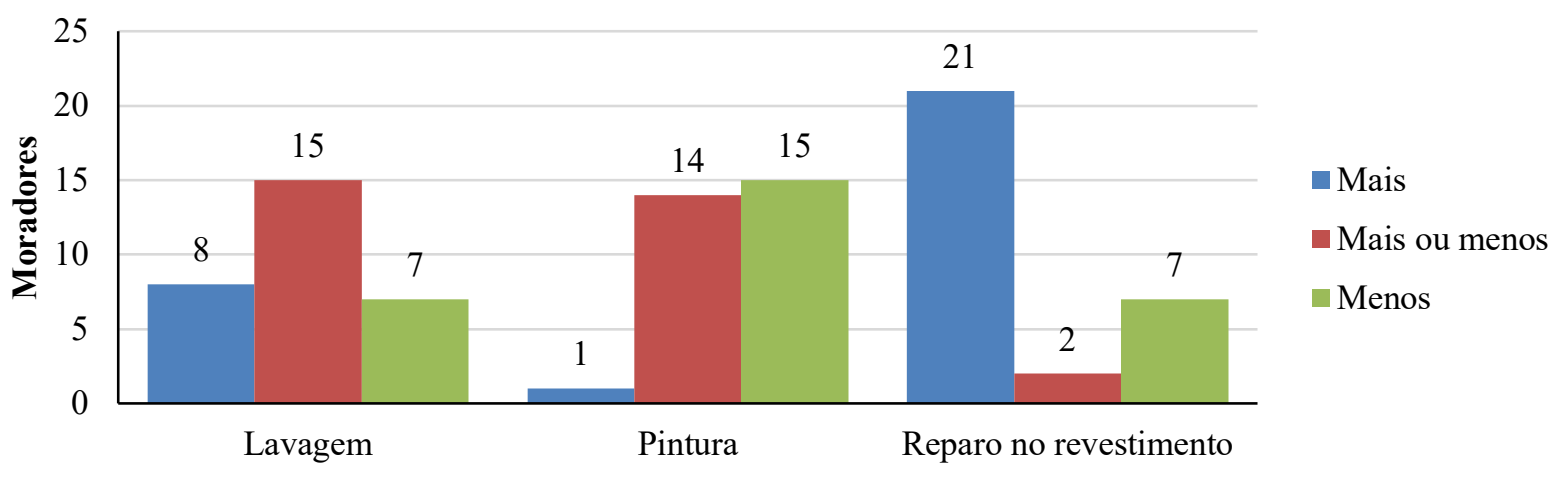

Figura 07. Necessidade das ações de manutenção do Residencial Regente

Observa-se que a maioria dos respondentes acham mais necessário o reparo do revestimento. Para melhor compilação dos dados foram colocados pesos a fim de obter a porcentagem da necessidade das ações de manutenção. As porcentagens estão apresentadas na Figura 08.

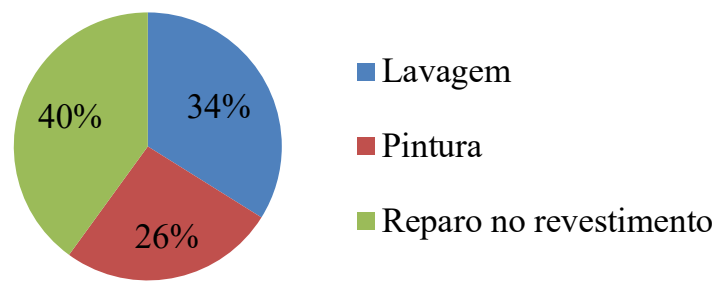

Figura 08. Prioridade de manutenção das fachadas do Residencial Regente.

Para finalizar, foi requerido aos moradores que avaliassem de maneira visual a situação atual dos prédios e classificassem entre boa, razoável e ruim. Conforme a Figura 09, 67\% dos respondentes consideram a situação atual das fachadas dos prédios ruim, contra 33\% que consideram como razoável. Nenhum respondente qualificou as fachadas como boas.

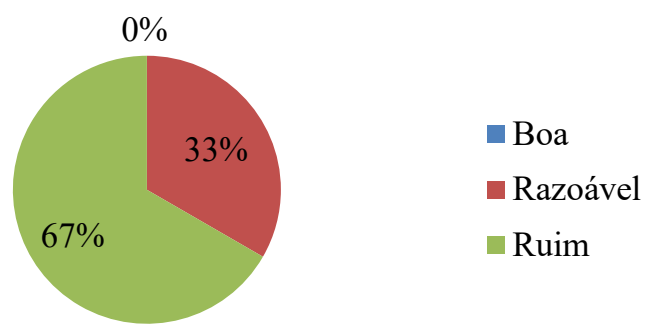

Figura 09. Avaliação da situação atual dos prédios do Residencial Regente.

\subsection{Residencial Jardins da Baronesa}

As primeiras perguntas do formulário permitem traçar um perfil do usuário respondente. A maioria dos respondentes foram do sexo feminino (63\%), 50\% entre 25 e 39 anos e $27 \%$ entre 40 a 59 anos. A maioria dos respondentes (50\%) é proprietário do apartamento, seguido pelos arrendatários, que representam 47\% dos moradores, o restante são inquilinos (3\%).

Foram aplicados formulários com moradores dos dois edifícios do Residencial Jardins da Baronesa, sendo $57 \%$ dos respondentes dos Blocos 4, 5 ou 6 e $43 \%$ dos Blocos 1, 2 ou 3, espalhados entre os quatro pavimentos do conjunto, sendo $37 \%$ do $1^{\circ}$ pavimento, $20 \%$ do $2^{\circ}$ pavimento, $23 \%$ do $3^{\circ}$ pavimento e $20 \%$ do $4^{\circ}$ pavimento. 
Quanto à quantidade de moradores por unidade habitacional, 47\% dos apartamentos dos moradores respondentes são habitados por duas pessoas, seguidos de $23 \%$ por quatro ou mais pessoas, $20 \%$ por uma pessoa e $10 \%$ por três pessoas.

Quanto a satisfação do usuário em relação as manifestações patológicas, os moradores foram questionados se já haviam reparado nos problemas existentes nas fachadas dos prédios. A maioria dos respondentes afirmaram que sim (93\%), e quando questionados se estes problemas lhe incomodavam, $90 \%$ dos moradores responderam que sim.

Os moradores foram questionados sobre qual manifestação patológica chamava mais sua atenção, sendo as respostas apresentadas na Figura 10.

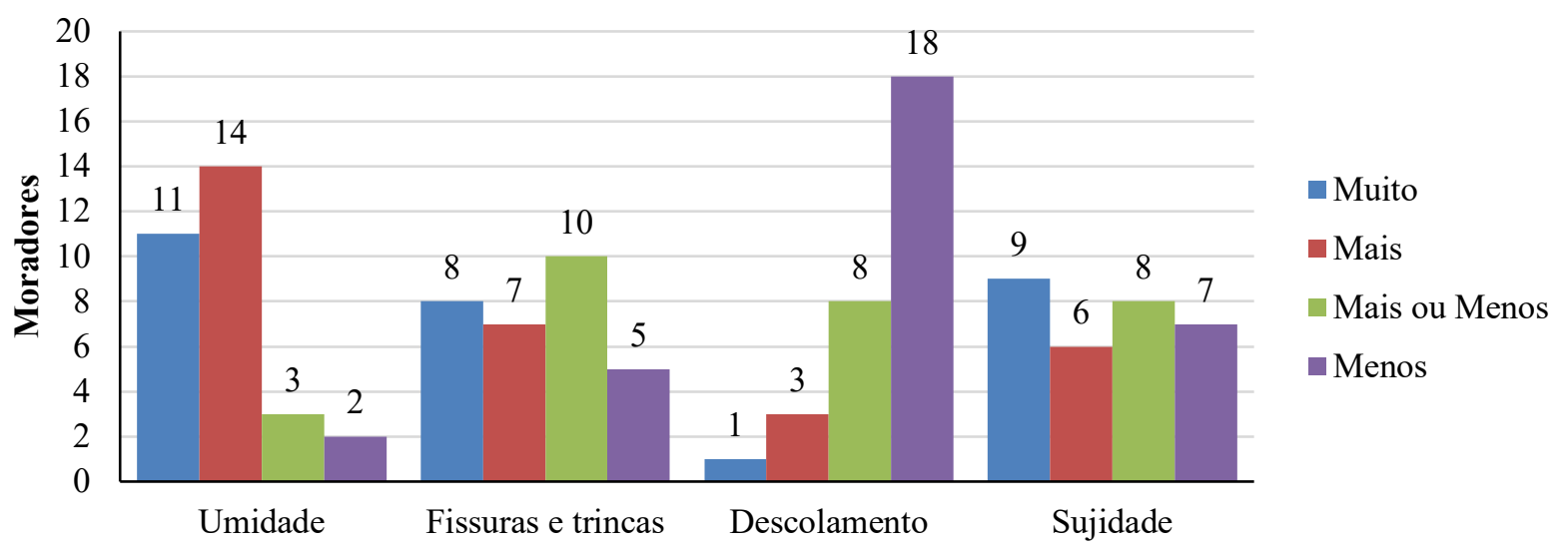

Figura 10. Manifestação patológica mais relevante no Residencial Jardins da Baronesa.

Para cada grau de visibilidade do usuário em relação a cada manifestação patológica foi obtida a porcentagem de relevância de cada dano para o morador, apresentadas na Figura 11. As manifestações patológicas que mais chamam a atenção dos moradores é a umidade (31\%), seguida pela sujidade (27\%), fissuras e trincas $(26 \%)$ e descolamento de revestimento (16\%). Apesar da alta incidência de fissuras e trincas no residencial, sua maior parte fica na fachada de fundos do Edifício A, portanto não é visualizada pela maioria dos moradores.

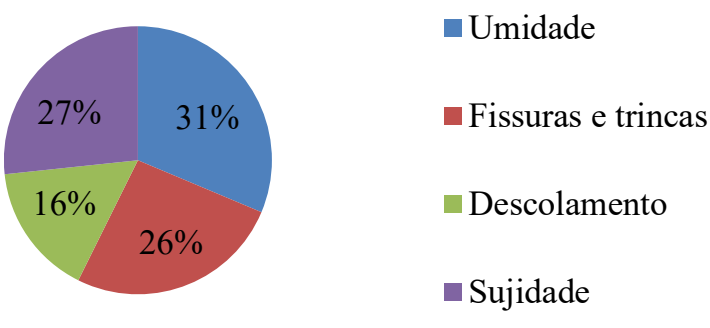

Figura 11. Relevância das manifestações patológicas no Residencial Jardins da Baronesa.

Sobre a manutenção das fachadas, todos os respondentes consideraram ações necessárias de manutenção, inclusive os que não haviam reparado nos problemas. Porém, 70\% nunca realizaram algum tipo de reclamação com a imobiliária sobre os problemas das fachadas. Os moradores foram perguntados qual manutenção, entre lavagem, pintura e reparo no revestimento, eles achavam mais necessário. As respostas estão na Figura 12. 


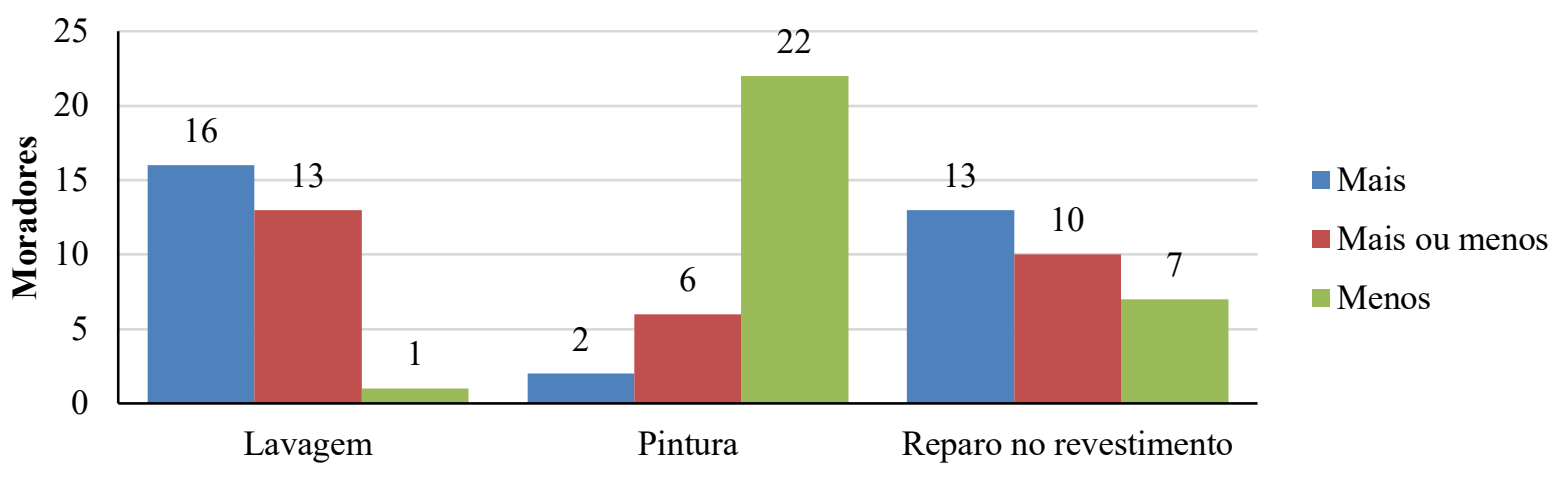

Figura 12. Necessidade das ações de manutenção do Residencial Jardins da Baronesa

Observa-se que a maioria dos respondentes acham menos necessário a pintura. Para melhor compilação dos dados foram colocados pesos, a fim de obter a porcentagem da necessidade das ações de manutenção, apresentadas na Figura 13.

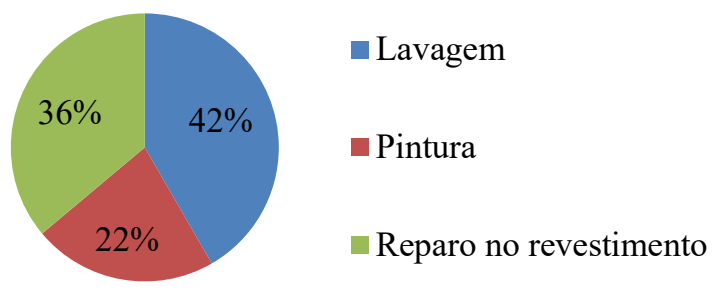

Figura 13. Prioridade de manutenção das fachadas do Residencial Jardins da Baronesa.

Para finalizar, foi requerido aos moradores que avaliassem de maneira visual a situação atual dos prédios e classificassem entre boa, razoável e ruim. Conforme a Figura 14, 70\% dos respondentes consideram a situação atual das fachadas dos prédios ruim, contra $30 \%$ que consideram como razoável. Assim como no Residencial Regente, nenhum respondente qualificou as fachadas como boas.

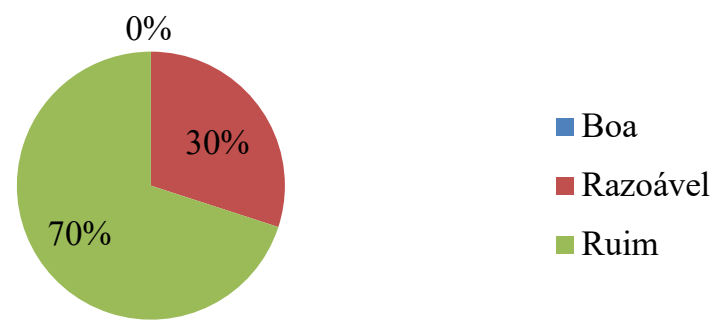

Figura 14. Avaliação da situação atual dos prédios do Residencial Jardins da Baronesa.

\subsection{Residencial Estrela Gaúcha}

No Residencial Estrela Gaúcha, a maioria dos respondentes foram do sexo feminino (73\%) entre 10 e $59 \operatorname{anos}(33 \%)$ e até 24 anos (30\%). Maior parte dos respondentes $(57 \%)$ é arrendatário do apartamento, seguido pelos proprietários (30\%), sendo o restante inquilinos (13\%).

Foram aplicados formulários com moradores dos quatro edifícios do Residencial Estrela Gaúcha, sendo $33 \%$ dos respondentes dos Blocos 1, 2, 3 ou 4, 30\% dos Blocos 12, 13, 14 ou 15, 20\% dos Blocos 8, 9, 10 ou 11 e 17\% dos Blocos 5, 6 ou 7, espalhados entre os cinco pavimentos do 
conjunto, sendo $33 \%$ do $2^{\circ}$ pavimento, $27 \%$ do $3^{\circ}$ pavimento, $17 \%$ do $1^{\circ}$ pavimento, $13 \%$ do $4^{\circ}$ pavimento e $10 \%$ do $5^{\circ}$ pavimento.

Quanto à quantidade de moradores por unidade habitacional, 43\% dos apartamentos dos moradores respondentes são habitados por três pessoas, seguidos de $27 \%$ por uma pessoa, $17 \%$ por quatro ou mais pessoas e $13 \%$ por duas pessoas.

Quanto a satisfação do usuário em relação as manifestações patológicas, os moradores foram questionados se já haviam reparado nos problemas existentes nas fachadas dos prédios. A maioria dos respondentes afirmaram que $\operatorname{sim}(80 \%)$, e quando questionados se estes problemas lhe incomodavam, $73 \%$ dos moradores responderam que sim.

Os moradores foram questionados sobre qual manifestação patológica chamava mais sua atenção, estando as respostas apresentadas na Figura 15.

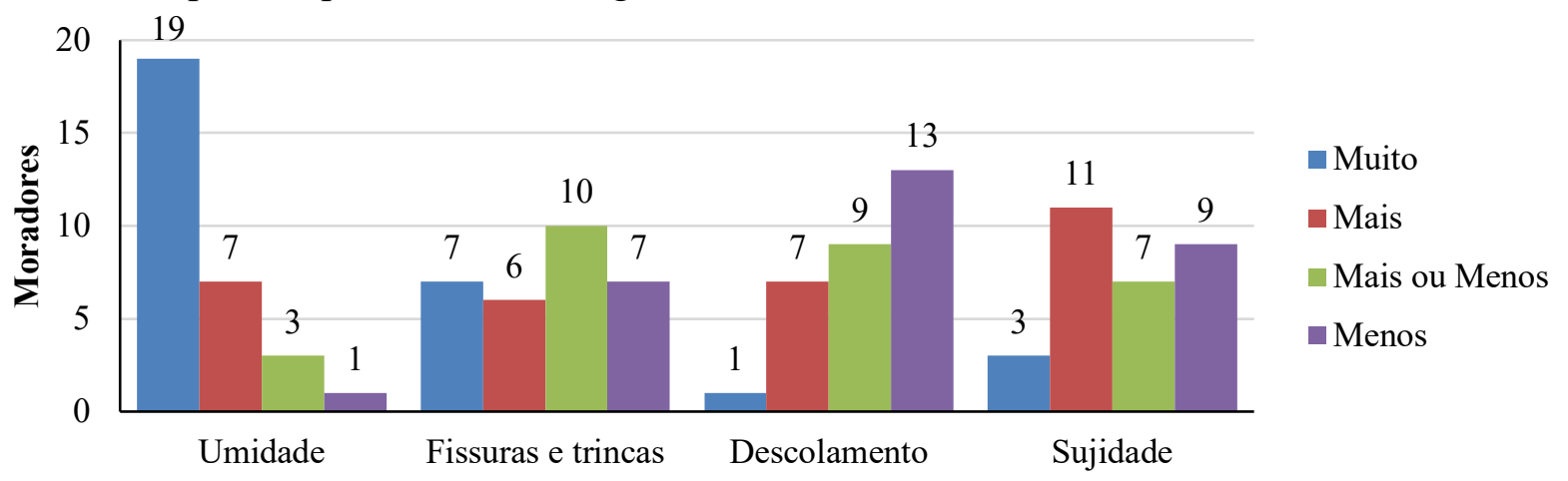

Figura 15. Manifestação patológica mais relevante no Residencial Estrela Gaúcha.

Para o grau de visibilidade do usuário em relação a cada manifestação patológica foram colocados pesos a fim de obter a porcentagem de relevância de cada dano para o morador. As porcentagens estão apresentadas na Figura 16. As manifestações patológicas que mais chamam a atenção dos moradores é a umidade (34\%), seguida pela sujidade (23\%), fissuras e trincas (25\%) e descolamento de revestimento (18\%). No Residencial Estrela Gaúcha, a manifestação patológica mais incidente é a umidade, portanto os moradores conseguem observar tal fato.

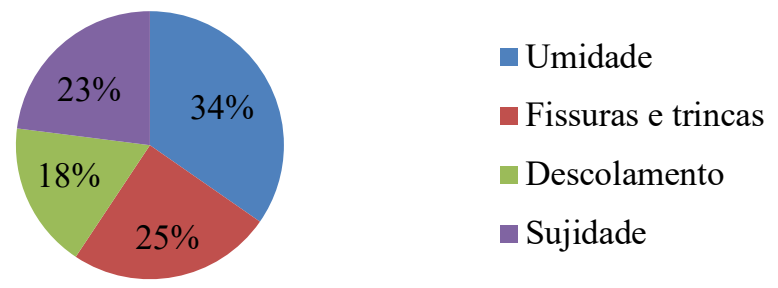

Figura 16. Relevância das manifestações patológicas no Residencial Estrela Gaúcha.

Sobre a manutenção das fachadas, todos os respondentes consideraram necessárias atividades de manutenção, inclusive os que não haviam reparado nos problemas. Porém, 70\% nunca realizaram algum tipo de reclamação com a imobiliária sobre os problemas das fachadas. Os moradores foram perguntados qual manutenção, entre lavagem, pintura e reparo no revestimento, eles achavam mais necessário, sendo as respostas apresentadas na Figura 17. 


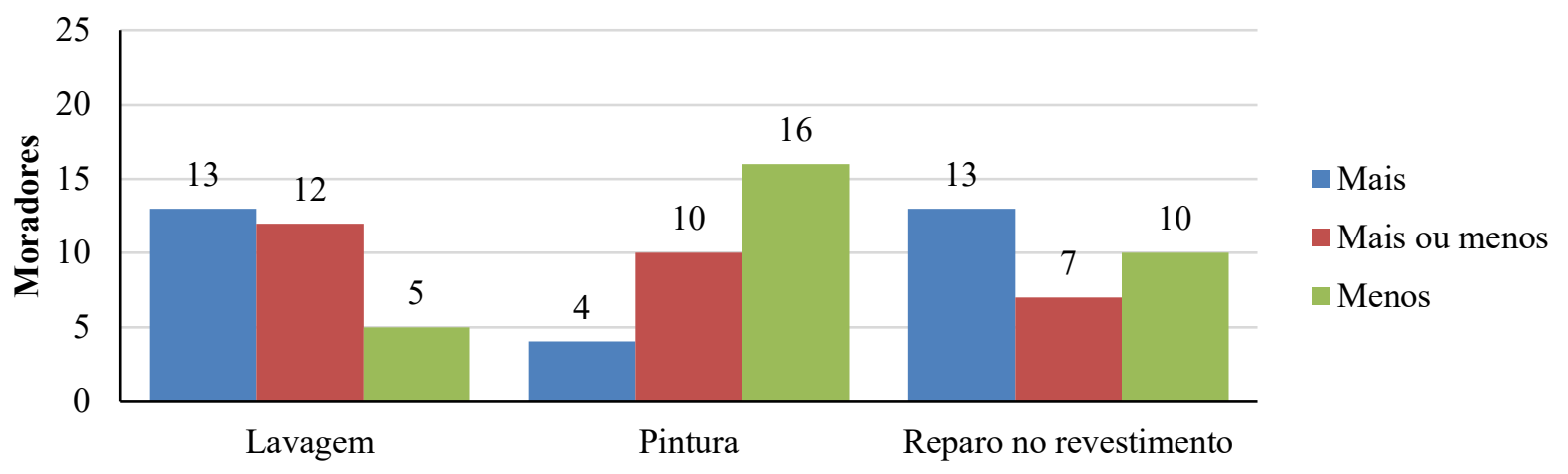

Figura 17. Necessidade das ações de manutenção do Residencial Estrela Gaúcha.

Observa-se que a maioria dos respondentes acham menos necessário a pintura, e se dividem entre lavagem e reparo no revestimento como ação de manutenção mais necessária. Para melhor compilação dos dados foram colocados pesos a fim de obter a porcentagem da necessidade das ações de manutenção, as quais estão apresentadas na Figura 18.

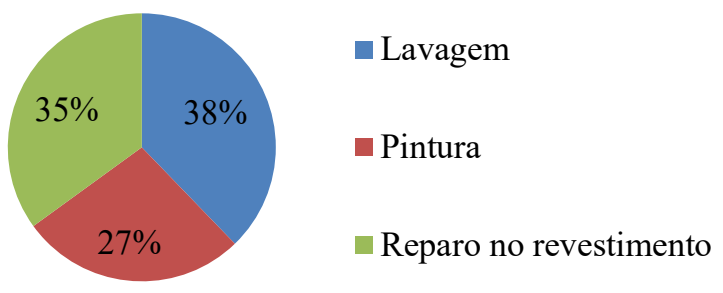

Figura 18. Prioridade de manutenção das fachadas do Residencial Estrela Gaúcha.

Para finalizar, foi requerido aos moradores que avaliassem de maneira visual a situação atual dos prédios e classificação entre boa, razoável e ruim, estando as respostas mostradas na Figura 19. Conforme o gráfico, $53 \%$ dos respondentes consideram a situação atual das fachadas dos prédios como razoável, contra $40 \%$ que consideram como ruim.

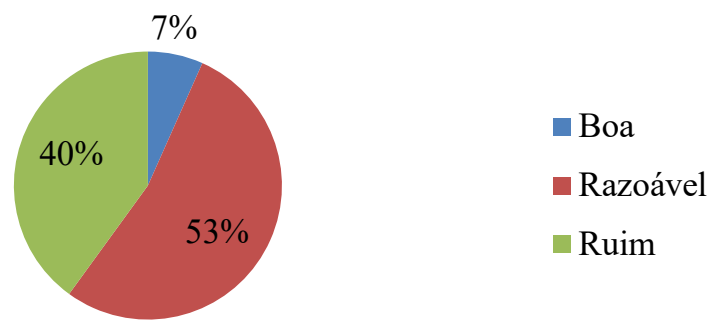

Figura 19. Avaliação da situação atual dos prédios do Residencial Estrela Gaúcha.

Entre os três conjuntos habitacionais objetos deste estudo, o Residencial Estrela Gaúcha, da modalidade Especial, foi o único com alguma avaliação positiva das fachadas, conforme Figura 20 Tal fato pode ser justificado por ser o conjunto habitacional com menor incidência de manifestações por metro quadrado. 


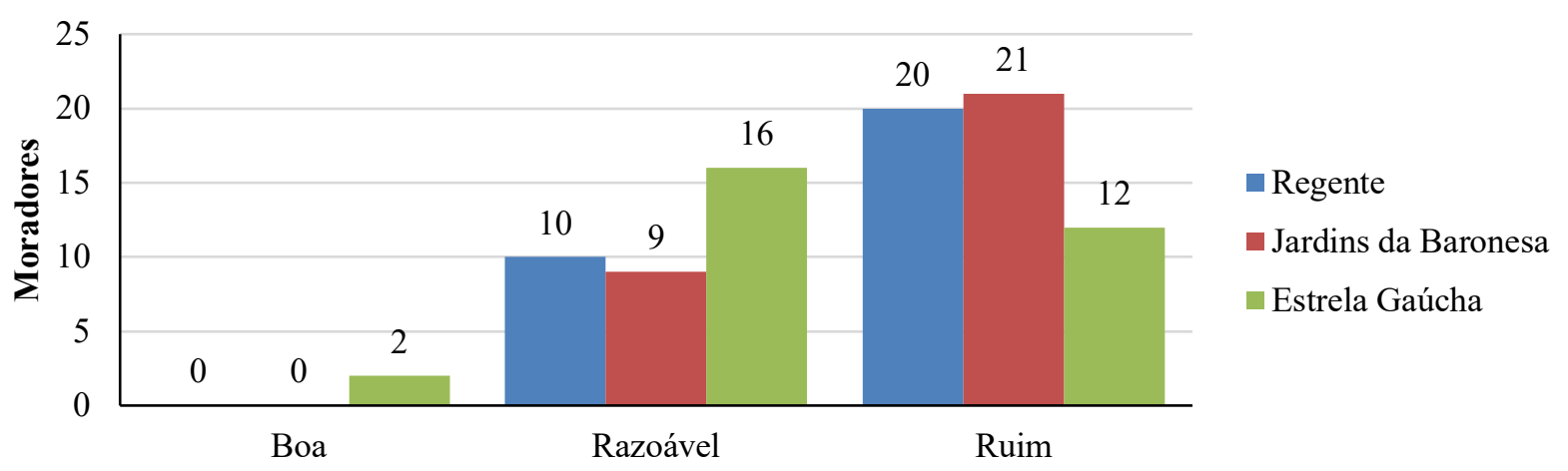

Figura 20. Avaliação da situação atual dos três conjuntos habitacionais.

\section{DISCUSSÕES}

A satisfação dos moradores com o conjunto habitacional está totalmente relacionada a aparências das edificações (Reis; Lay, 2010). Os resultados indicam que a aparência externa dos residenciais é importante para a satisfação do usuário. $\mathrm{O}$ conjunto habitacional com melhor avaliação das fachadas pelos usuários é o Residencial Estrela Gaúcha, residencial com menor incidência de manifestações patológicas por metro quadrado, como mostra a Figura 21.

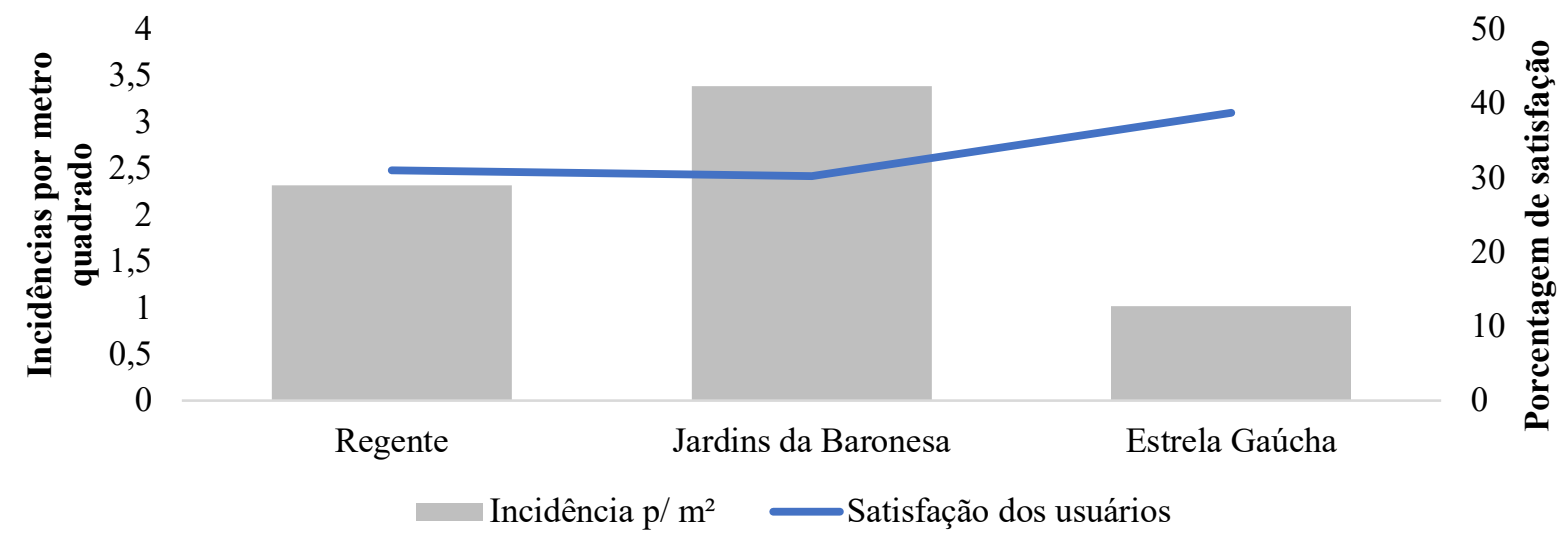

Figura 21. Incidência de manifestações patológicas x Satisfação do usuário.

Nota-se que o conjunto com maior insatisfação com a situação atual das fachadas dos prédios é o conjunto com maior incidência de manifestações patológicas por metro quadrado.

De acordo com Reis e Lay (2010), a avaliação da aparência das edificações pode ser afetada pelo nível de manutenção do conjunto. $\mathrm{O}$ grande número de moradores insatisfeitos de um conjunto habitacional pode ser explicado pela falta de conservação dos prédios, sem pintura, com queda de reboco ou existência de rachaduras, que denota problemas estruturais.

Medvedovski (2010) comenta que a unidade habitacional é um sistema complexo que agrega bens e serviços, portando não basta a casa ser entregue ao usuário final, deve ser operada e mantida adequadamente.

A incidência de manifestações patológicas nos revestimentos das fachadas externas, mesmo que originadas no projeto ou execução, podem ser solucionadas com atividades de manutenção, como reparo, lavagem e pintura. Agravada pelo fato que segundo Uemoto (1988), todas as pinturas se deterioram rapidamente ao longo do tempo e sua durabilidade está ligada ao tipo da tinta, do substrato e à exposição a qual é submetida e presença de agentes biológicos, como fungos, algas, mofo e limo, agrava a deterioração da pintura. 
Porém, segundo Sanches e Fabricio (2009) é crítica a execução de ações de manutenção em habitações de interesse social, pois a disponibilidade de recursos dos moradores para reformas é limitada. Dessa forma, durante o projeto de novas habitações deve ser considerada a manutenibilidade das edificações.

\section{CONCLUSÕES}

Os métodos utilizados neste estudo permitiram avaliar a satisfação do usuário em relação ao estado de conservação dos empreendimentos, possibilitando a tomada de ações corretivas.

Neste contexto, a realização da Avaliação Pós-Ocupação não serviu apenas para a detecção de problemas dos objetos de estudo, mas para retroalimentação do processo de produção e uso das edificações. Os resultados devem ser levados em consideração em novas habitações de interesse social, propositando eliminar possíveis falhas e problemas, mas como também nas habitações existentes, possibilitando agregar informações que colaborem com a criação de planos de manutenção. A aplicação dos formulários possibilitou verificar que a degradação das fachadas, indicado pela incidência de manifestações patológicas, acarreta maior insatisfação dos moradores com as fachadas dos prédios devido ao seu mau aspecto.

\section{AGRADECIMIENTOS}

Os autores agradecem o apoio financeiro da CAPES (Fundação Coordenação de Aperfeiçoamento de Pessoal de Nível Superior) - Código Financeiro 001 - e o apoio do NEPAMAT (Núcleo de Estudos em Patologias e Materiais), PROGRAU (Programa de Pós-Graduação em Arquitetura e Urbanismo) e UFPel (Universidade Federal de Pelotas).

\section{REFERENCIAS}

ABNT - ASSOCIAÇÃO BRASILEIRA DE NORMAS TÉCNICAS. NBR 5674/2012:

Manutenção de edificações: Requisitos para o sistema de gestão de manutenção. Rio de Janeiro: ABNT, 2012.

CHIARELLI, L. M. Á. Habitação Social em Pelotas (1987 - 2010). Influências das políticas públicas na promoção de conjuntos habitacionais. 2014. 345f. Tese (Doutorado em História). Programa de Pós-Graduação em História da Faculdade de Filosofia e Ciências Humanas da Pontifícia Universidade Católica do Rio Grande do Sul (PUCRS), Porto Alegre, 2014.

JOHN, V. M. Aproveitamento de resíduos sólidos como materiais de construção. In: CARNEIRO, A.P. et al. (Orgs.). Reciclagem de entulho para a produção de materiais de construção. Salvador: EDUFBA, 2001. p.27-45.

MEDVEDOVSKI, N. S. (coord.). Geração de indicadores de qualidade dos espaços coletivos em EHIS - INQUALHIS. Relatório final de conclusão de Pesquisa do Núcleo de Pesquisa em Arquitetura e Urbanismo. Pelotas: FINEP/HABITARE. 2010.

MEDVEDOVSKI, N. S.; CHIARELLI, L.M.A; TILLMANN, P; QUANDT, M.M.. Gestão habitacional para uma arquitetura sustentável. Ambiente construído, v. 5, n. 3, p. 49-61, jul./set. 2005. 
ORNSTEIN, S. W.; ONO, R.; OLIVEIRA, F. L. de. Em busca da qualidade na habitação social no Brasil: instrumentos para a Avaliação Pós-Ocupação (APO) aplicada a sistemas construtivos inovadores. Anais... Covilhã: Universidade da Beira Interior, 2017.

REIS, A. T. L.; LAY, M. C. D. O projeto da habitação de interesse social e a sustentabilidade social. Ambiente construído, v. 10, n. 3, p. 99-119, Set. 2010.

ROMÉRO, M. A.; ORNSTEIN, S. Avaliação Pós-ocupação: Métodos e Técnicas Aplicados à Habitação de Interesse Social. In. ASSOCIAÇÃO NACIONAL DE TECNOLOGIA DO AMBIENTE CONSTRUÍDO, 1, Porto Alegre, 2003. Anais... Porto Alegre: ANTAC, 2003. Coleção Habitare.

SANCHES, I. D.; FABRICIO, M. M. A importância do projeto na manutenção de HIS. In: SIMPÓSIO BRASILEIRO DE GESTÃO E ECONOMIA DA CONSTRUÇÃO-SIBRAGEC. Anais... 2009.

SHIMBO, L. Z.; MARTINS, M. E. A questão da manutenção de sistemas construtivos inovadores para habitação. In: FABRICIO, M. M.; ONO, R. (Orgs.). Avaliação de desempenho de tecnologias construtivas inovadoras: manutenção e percepção dos usuários. Porto Alegre: ANTAC, 2002. p.55-66.

SILVA, V. M. B. Manifestações Patológicas em Fachadas de Empreendimentos do Programa de Arrendamento Residencial na Cidade de Pelotas/RS: Residenciais Solar das Palmeiras e Paraíso. 2016. 148f. Dissertação (Mestrado em Arquitetura e Urbanismo) - Programa de Pós-Graduação em Arquitetura e Urbanismo, Faculdade de Arquitetura e Urbanismo, Universidade Federal de Pelotas, Pelotas, 2016.

STUCKERT, T. C.; SOBRINHO JÚNIOR, A. Patologias em habitações de interesse social. Revista InterScientia, v. 4, n. 2, p. 109-122, 2016.

THOMAZ, E. Trincas em edificações: causas e mecanismos de formação. In: INSTITUTO DE PESQUISAS TECNOLÓGICAS DO ESTADO DE SÃO PAULO. Tecnologia de edificações. São Paulo: Ed. Pini: IPT, 1988. p.555-560.

THOMAZ, E. Trincas em edifícios: causas, prevenção e recuperação. São Paulo: Pini/IPT/EPUSP, 1989.

UEMOTO, K. L. Patologia: Danos causados por eflorescência. In: INSTITUTO DE PESQUISAS TECNOLÓGICAS DO ESTADO DE SÃO PAULO. Tecnologia de edificações. São Paulo: Ed. Pini: IPT, 1988. p.561-564.

VIEIRA, F. do N. Proposta de elaboração de plano de manutenção para edificações a partir da obrigatoriedade legal da inspeção predial no contexto urbano das Cidades. Rio de Janeiro, 2015. Dissertação (Mestrado) - Programa de Engenharia Urbana, Escola Politécnica, Universidade Federal do Rio de Janeiro, Rio de Janeiro, 2015.

ZUO, J.; ZHAO, Z. Green building research-current status and future agenda: A review. Renewable and Sustainable Energy Reviews, v. 30, p. 271-281, 2014. 